\title{
REGULATORY NEGOTIATIONS AND OTHER RULEMAKING PROCESSES: STRENGTHS AND WEAKNESSES FROM AN INDUSTRY VIEWPOINT
}

\author{
ELLEN SIEGLER ${ }^{\dagger}$
}

\section{INTRODUCTION}

I participated in the Duke Law Journal's March 7, 1997 Administrative Law Conference on regulatory negotiations to provide the perspective of a negotiator who represented a trade organization in a regulatory negotiation (reg neg). The reg neg in which I participated was convened by the United States Environmental Protection Agency (EPA). I represented the American Petroleum Institute (API), a trade organization that has been involved in a variety of processes (including reg negs) through which EPA has developed, or is developing, regulations.

In this Article, I will describe some of API's experiences in recent EPA rulemaking processes, principally ruleinakings conducted pursuant to the Clean Air Act. ${ }^{1}$ Then I will present iny personal views on the advantages and disadvantages of reg negs coinpared with other ruleinaking processes from the viewpoint of an mdustry trade association.

I represented API in a reg neg addressing the control of emission of hazardous air pollutants froin equipinent leaks at synthetic organic chemical plants. ${ }^{2}$ API was invited to participate in this negotiation because control of equipnient leaks at refineries is in many respects similar to control of equipinent leaks at chemical plants, and API was advised that the negotiated rule for chemical plants (assuming the negotiations were successful) would

$\dagger$ Senior Attorney, American Petroleum Institute.

1. 42 U.S.C. $\S \S 7401-7671 q$ (1994). I described reg negs, based largely on my own experience with the equipment leaks reg neg, in Ellen Siegler, Regulatory Negotiations: $A$ Practical Perspective, 22 Envtl. L. Rep. (Envtl. L. Inst.) 10,647 (Oct. 1992).

2. The product of these negotiations was incorporated in the EPA's National Emission Standards for Organic Hazardous Air Pollutants for Equipment Leaks, 40 C.F.R. $\S \S$ 63.160-.182 (1996). 
establish a framework that was likely to be used subsequently in a similar rule for refineries.

The equipment leaks negotiation commenced in 1989 and produced an agreement on requirements that EPA incorporated into a final rule on April 22, 1994, ${ }^{3}$ pursuant to section 112(d) of the Clean Air Act. ${ }^{4}$ As API had been advised, concepts adopted $\mathrm{m}$ this rule were later included in a similar rule for petroleuin refineries. $^{5}$

API also participated in a regulatory negotiation EPA convened to develop requirements for the composition of reformulated and oxygenated fuels. ${ }^{6}$ The "fuels reg neg" began in 1990 and ended in agreement on a set of principles to guide EPA rulemaking in August $1991 .^{7}$ I was not directly involved in this negotiation, but I describe it here in some detail because it is largely responsible for API's disillusionment with reg negs. API's experiences in two reg negs and nnmerous other processes may be useful to others contemplating participation in a reg neg and seeking to understand the benefits and drawbacks of reg negs from a participant's standpoint.

\section{Difficulties ENCOUNTERed By TRAde Associations IN THE REg Neg PROCESS}

A reg neg is a cumbersome process for everyone involved. It is particularly complicated for a trade association, lowever, because several negotiations are conducted simultaneously during the reg neg process. At API, decisions on regulatory issues are made by a committee process; committees are composed of representatives of member companies who, it should be noted, are competi-

3. See National Emission Standards for Hazardous Air Pollutants for Source Categories; Organic Hazardous Air Pollutants from the Synthetic Organic Chemical Manufacturing Industry and Other Processes Subject to the Negotiated Regulation for Equipment Leaks, 59 Fed. Reg. 19,402 (1994) (codified at 40 C.F.R. $\S \S 63.160-182$ (1996)).

4. See 42 U.S.C. \& 7412(d).

5. See National Emission Standards for Hazardous Air Pollutants: Petroleum Refineries, 60 Fed. Reg. 43,244 (1995) (codified at 40 C.F.R. pt. 63, subpt. cc).

6. This negotiation was convened pursuant to sections $211(\mathrm{k})$ and $211(\mathrm{~m})$ of the Clean Air Act. See 42 U.S.C. \& 7545(k), (m).

7. See Agreement Reached on Clean Vehicles Fuels, Environmental News (EPA Press Release Aug. 16, 1991); Environmental Protection Agency Clean Fuels Advisory Comm. Outline of Supplemental Proposed Rules and Guidances for Reformulated Gasoline, Antidumping and Oxygenated Gasoline (Aug. 16, 1991) (both on file with the Duke Law Journal). 
tors. In all regulatory matters, members negotiate in committees; they often must then report the results of the negotiations to, and have them approved by, committees at their respective companies before they can agree on an API consensus position. This type of intra-association negotiation is more intense in a reg neg than in a traditional rulemaking. because member companies realize that if the reg neg is successful, the trade association will agree to not litigate if the agency promulgates a rule consistent with the agreement reached. ${ }^{8}$ Because the stakes are so high for the industry, tentative commitments made in a reg neg require a higher level of ratification.

Negotiations conducted on behalf of a trade association in a reg neg are also complicated by the frequent need for those representing the organization in the reg neg to check back with committee members before responding to proposals or counter-proposals made by others at the reg neg table. While official representatives are given some latitude, there may be significant limits placed on their ability to negotiate because proposals affect competitors within the trade association differently. Standards that one company can easily achieve (for exaniple, because the company has controls already in place as a result of stringent state requirements) may be very expensive for another coinpany. In a highlycompetitive industry where profit margins are low, like the petroleum refining industry, these differences can significantly impact a company's fortunes.

A second sphere of negotiations exists when several different industries are involved in the reg neg. In the equipment leaks reg neg, the chemical industry and the petroleum industry had to negotiate on some issues because certain control requireinents are easier to achieve in chemical plants than in refimeries. In the fuels reg neg, there were even greater differences ainong industry participants. For exaniple, refiners sought the greatest aniount of flexibility in fuels requirements; but too much flexibility presented difficulties for the automobile manufacturers, who would design engines to use the new fuels.

Finally, of course, the reg neg involves intense negotiations at the formal reg neg table, at which representatives of state and

8. Such agreements only bind the agency to a proposed rule, not a final rule. However, if the final rule was consistent with the agreement, the agreement not to litigate would continue to be effective. 
federal agencies, public interest environmental groups, and perhaps others, join industry representatives. Building enough trust among these groups to reach an agreement is a long and difficult undertaking. The complex and cumbersoine nature of the reg neg process is one reason why API does not greet with enthusiasm invitations to participate in a reg neg.

\section{History OF tHe Fuels REg NEG}

The fuels reg neg illustrates many of the difficulties and frustrations that can arise when a reg neg process is used to resolve complex and highly political issues.

Shortly after Congress amended the Clean Air Act in November 1990, ${ }^{9}$ EPA convened a reg neg to address the Act's new requirements for reformulated gasoline (RFG). ${ }^{10}$ Representatives from EPA, the Department of Energy, automobile manufacturers, petroleum refiners and marketers, the oxygenate industry, states, environmental groups and API participated in the reg neg. Because the Clean Air Act directed EPA to promulgate the RFG rules within one year, ${ }^{11}$ EPA encouraged participation by advising potential reg neg participants that the Agency would not have the time and resources to meet with them imdividually. For example, EPA advised API that the reg neg would proceed regardless of whether or not API participated. Under these circumstances, API agreed to participate.

The reg neg ended in August 1991 with an agreement on principles for EPA to follow in the forthcoming RFG rule. The RFG rule was promulgated in two stages: a main RFG rule was issued on February 16, 1994;12 a supplemental RFG rule was promulgated on August 2, 1994. ${ }^{13}$

9. Act of Nov. 15, 1990, Pub. L. No. 101-549, 104 Stat. 2399 (codified as amended in scattered sections of 42 U.S.C.).

10. Pursuant to section 211(k) of the amended Act, see 42 U.S.C. $\& 7545(k)$, EPA was directed to issue rules to reduce emissions of ozone-forming volatile organic compounds during certain times of the year and to reduce toxic pollutants during the entire year, through the requirement of reformulation of gasoline in certain ozone nonattainment areas. A related provision of the Act, section $211(\mathrm{~m})$, see 42 U.S.C. $\S$ $7545(\mathrm{~m})$, contemplated state oxygenated gasoline programs for carbon monoxide nonattainment areas.

11. See 42 U.S.C. $\$ 7545(k)(1)$.

12. See Regulation of Fuels and Fuel Additives: Standards for Reformulated and Conventional Gasoline, 59 Fed. Reg. 7716 (1994) (codified at 40 C.F.R. pt. 80).

13. See Regulation of Fuels and Fuel Additives: Renewable Oxygenate Requirement 
The main RFG rule raised one issue of significance to the reg neg: nitrogen oxides (NOx). Section 211(k)(2)(A) of the Clean Air Act provided that emissions of NOx arising from RFG could be no greater than such emissions from vehicles using "baseline" fuels. ${ }^{14}$ During the $1991 \mathrm{reg}$ neg, there was some discussion of whether the "no NOx increase" provision of the statute allowed de minimis NOx increases. No agreement was reached on this issue, however. There was no discussion during the reg neg of NOx reductions.

In February 1993, however, well into the rulemaking and much to the petroleum industry's surprise, EPA proposed to require a substantial NOx reduction. The final RFG fuels rule, issued in February 1994, incorporated a somewhat scaled back, but still substantial, requirement for NOx reduction. ${ }^{15}$ API considered this requirement a violation of the spirit of the reg neg. API felt that if EPA had intended to require NOx reductions, the issue should have been discussed during the reg neg. API chose not to challenge this requirement in legal proceedings but, in December 1995, API submitted to EPA a petition for reconsideration and repeal of the RFG NOx standard. EPA denied the petition on March 12, 1997. ${ }^{16}$

In 1994, as a result of political pressure from the ethanol manufacturers, EPA issued a second rule relating to RFG. $^{17}$ This rule imposed an "ethanol mandate," requiring that thirty percent of the oxygen in RFG be derived from renewable sources. ${ }^{18}$ EPA acknowledged that this requireinent would benefit manufacturers of ethanol, the only renewable oxygenate then produced in large quantities. $^{19}$

API regarded the ethanol mandate as a betrayal of the agreeinent that concluded the fuels reg neg, which was designed not to favor particular fuel additives. API subsequently challenged the

in Reformulated Gasoline, 59. Fed. Reg. 39,258 (1994) (codified at 40 C.F.R. pt. 80) [hereinafter Renewable Oxygenate Requirement].

14. See 42 U.S.C. $\& 7545(\mathrm{k})(2)(\mathrm{A})$.

15. See Regulation of Fuels and Fuel Additives: Standards for Reformulated and Conventional Gasoline, 59 Fed. Reg. 7716, 7753-54 (1994) (codified at 40 C.F.R. pt. 80).

16. See Regulation of Fuels and Fuel Additives: Standards for Reformulated Gasoline, 62 Fed. Reg. 11,346, 11,360 (1997) (to be codified at 40 C.F.R. pt. 80).

17. See Renewable Oxygenate Requirement, supra note 13 , at $39,258,39,261$.

18. See id. at 39,261 .

19. See id. 
ethanol mandate. ${ }^{20}$ After first issuing a stay, the United States Court of Appeals for the District of Columbia vacated the rule in April $1995 .{ }^{21}$ The court held that the ethanol mandate plainly exceeded EPA's authority under the Clean Air Act. ${ }^{22}$

In vacating the ethanol mandate, the D.C. Circuit did not address the issue of whether EPA had violated the reg neg agreement; API did not raise the issue to the court. API attorneys had cautioned petroleum industry representatives, during and after the reg neg, that they should not consider the reg neg agreement an enforceable contract; rather, the attorneys advised that the agreement should be regarded as an unenforceable "gentlemen's agreement." The recent case of USA Group Loan Services, Inc. $v$. Riley, ${ }^{23}$ in which the Seventh Circuit addressed in dicta the nature of reg neg agreements, demonstrates that this advice was appropriate. ${ }^{24}$

\section{LESSONS LEARNED FROM THE FUELS REG NEG}

There can be benefits to participating in a successful reg neg. First, the opportunity for participants to discuss issues and confront each other sometimes leads to a more creative and more practical regulatory approach than would have occurred in a traditional rulemaking process, in which parties with different, adverse positions would participate largely by submitting written comments on a proposed rule. Second, the consensus process-with its expectation of avoiding litigation over final rule-may persuade the agency to adopt a nore creative legal interpretation than it might have otherwise adopted for the purpose of reaching a result that all parties agree makes sense. Third, a successful reg neg can provide greater certainty than the traditional rulemaking process that a regulation will not change between agreenent and proposal or between proposal and a final rule. This certainty is extremely valuable to industry, especially if compliance entails inajor con-

20. See American Petroleum Inst. v. EPA, 52 F.3d 1113, 1115 (D.C. Cir. 1995).

21. See id.

22. See id. at 1121.

23. 82 F.3d 708 (7th Cir. 1996).

24. In USA Group Loan Services, the Seventh Circuit stated that "the Negotiated Rulemaking Act did not make the promise [to abide by a consensus reached by the parties] enforceable." Id. at 714. Rather, the Negotiated Rulemaking Act "simply creates a consultative process in advance of the more formal arms' length procedure of notice and comment rulemaking." Id. at 715. 
struction projects, which are costly and require years of advance planning.

The fuels reg neg demonstrates, however, that these benefits are not always realized even if the reg neg ends im an agreement among the parties. For example, one of the most important benefits API sought in the fuels reg neg was a degree of certainty that the informal agreement would be implemented without major changes sufficient to allow API members to plan to meet Clean Air Act fuels requirements until at least the year 2000. At the conclusion of the reg neg, API believed it had achieved this objective. The events that occurred after completion of the reg neg-the NOx reduction requirements and the ethanol mandate, including the ensuing litigation over the ethanol mandate and the petition for reconsideration regarding the NOx requirement-taught API that this benefit can be taken away by an agency for political or other reasons.

The industry also thought it had secured sufficient leadtime by reaching a reg neg agreement over three years before the start of the RFG program. However, the final RFG rule was issued two and one-half years after the reg neg agreement was signed, leaving the industry with less than one year to implement the program.

A second lesson is that the costs to participate in a reg neg are greater for industry than for other participants. This lesson is not new; API experienced the same phenomenon in the equipment leaks reg neg. The fuels reg neg, however, placed even greater demands than the equipment leaks reg neg on the petroleum industry, and these demands seem even more significant when they are viewed in the context of the disappearing benefits.

In the context of the fuels reg neg, API was required to satisfy certain resource demands. First, API had to educate other participants, some of whom had interests adverse to API's, about the production and distribution of motor vehicle fuels. API found it necessary to prepare educational materials explaining these matters, as well as statistical concepts necessary for an understanding of some of the techirical issues involved. ${ }^{25}$ API had no assurance, of course, that this information would not be used outside the reg neg. API representatives also continued to divulge information by

25. Conversation with Robert Greco, Staff Member, API, in Washington, D.C. (Mar. 19, 1997). 
answering technical questions about refinery processes and marketing practices throughout the negotiation.

A second major resource drain was the need for analysis of issues and for rapid communication within API. This need involved both staff-level personnel and high-level management representatives of API niember companies. Because fuels issues are of great concern to the companies, communication was essential. A group of about twenty member conipany executives made themselves available to participate in lengthy conference calls every two weeks for a period of over six months. ${ }^{26}$

Another related lesson was that environmental group participants have an advantage at the negotiating table. In the fuels reg neg, they were not required to educate other participants. Consequently, they did not have to establish their credibility as experts, as did most industry participants, who-in the fuels reg neg-had actually been selected because of their technical expertise. Environmental representatives also enjoyed the advantages of having well-developed negotiating skills and experience. In addition, they did not have to check back with their constituencies at every turn. State representatives shared some of these advantages with environmental representatives.

The experience of the fuels reg neg, in short, left API with the view that the costs of a reg neg can far outweigh its benefits and that the federal government can too easily find ways to walk away froin a deal.

\section{OTHER RULemaking Processes}

One should not examine reg negs solely im comparison to a traditional notice-and-comment rulemaking, in which an agency first publishes a proposed rule, allows interested persons thirty days (sometimes more) to comment, and then issues a final ruleall with little or no discussion among the agency, the regulated community, and other interested parties. EPA has departed significantly from this stereotype of the traditional rulemaking process in recent years in developing many of its Clean Air Act regulations. A whole range of processes in which groups of "stakeholders" inay be involved, generally under the requirements of the Federal Advisory Committee Act, ${ }^{27}$ has evolved in recent years. Depend-

26. Id.

27. Pub. L. No. $92-463,86$ Stat. 770 (1972) (codified as amended at 5 U.S.C. app. 
ing on the interests involved, the issues to be discussed, and other various factors, these processes can be preferable to the reg neg process.

\section{A. Improved Traditional Rulemaking}

From API's standpoint, the best approach to rule1naking often is what might be viewed as an improved version of the traditional agency notice-and-comment rulemaking process. This process can be an efficient way to develop a regulation if the regulation is not of broad applicability and is not particularly controversial.

API has been involved in this "improved traditional rulemaking" process in connection with a number of Clean Air Act regulations over the past several years. The process works as follows. In advance of a regulation's proposal date, API develops data and analyses, and it recommends and discusses regulatory approaches with the agency staff in individual meetings. So1netimes the data used will have been generated jointly by EPA and the industry. After initial ineetings, API inay generate additional data, analyses, and proposals in response to comments and questions from EPA representatives, who will have performed their own analyses of the relevant data. This process may continue after a rule has been proposed and even after promulgation if API has mitiated hitigation. The content of any industry-EPA ineetings is recorded in written summaries and is available as part of the public record.

EPA, API and others have used this procedure effectively in recent years in three rules EPA has promulgated pursuant to section 112(d) of the Clean Air Act. ${ }^{28}$ These rules are designed to restrict emissions of hazardous air pollutants from refineries, ${ }^{29}$ marine loading operations ${ }^{30}$ and gasoline distribution facilities. ${ }^{31}$

This process involves more nncertainty than does a reg neg. The agency does not make a commitinent that a rule will not

§§ 1-15 (1994)).

28. See 42 U.S.C. $\& 7412$ (d) (1994).

29. See National Emission Standards for Petroleum Refineries, 40 C.F.R. $\S \S$ 63.640-.654 (1996).

30. See National Emission Standards for Marine Tank Vessel Loading Operations, 40 C.F.R. $\S \S 63.560-.567$ (1996).

31. See National Emission Standards for Gasoline Distribution Facilities (Bulk Gasoline Terminals and Pipeline Breakout Stations), 40 C.F.R. $\S \S 63.420-.429$ (1996). 
change significantly before its proposal; changes may be made for a variety of reasons, such as in response to concerns raised by other interested parties with EPA staff. There is also a greater chance that the proposed rule may change between proposal and promulgation, and a corresponding increased possibility of litigation. Uncertainty also stems froin EPA control over the process itself. As in the fuels reg neg, EPA can decline to ineet with API or other interests individually if EPA determines that it lacks sufficient time and resources. In contrast, once a reg neg has begun, the parties involved have made a commitment to histen to each other for at least a reasonable period of time.

The improved traditional ruleinaking process used to develop the three Clean Air Act rules mentioned above appears to have been beneficial to both API and EPA. EPA was able to meet its deadlines for promulgating rules that will achieve significant reductions in emissions of hazardous air pollutants. Two of the three final rules (the petroleum refining rule and the inarine vessel loading rule) escaped litigation. API did challenge the third (gasoline distribution) rule, ${ }^{32}$ but the litigation was resolved through settlement discussions and minor ainendinents to the rule.

In March 1995, EPA announced its intention to institute another variation in the traditional rulemaking process for developing rules pursuant to section 112(d) of the Clean Air Act. ${ }^{33}$ EPA was under the pressure of statutory deadlines to issue dozens of source category ${ }^{34}$ regulations pursuant to section $112(d)$ by the year $2000^{35}$ and announced a new "MACT Partnership" program. ${ }^{36}$ The first phase of the new approach to rulemaking, development of a "Presumptive MACT," involved several steps." In the first step, known as the Presumptive MACT meeting, EPA 1995).

32. See American Petroleum Inst. v. EPA, No. 95-1098 (D.C. Cir. filed Feb. 9,

33. "MACT" is an acronym for "maximum achievable control technology," the statutory basis for hazardous air pollutant regulations issued pursuant to the Act. See 42 U.S.C. \& 7412(d)(2) (1994).

34. The regulations apply to those source categories listed pursuant to section $112(\mathrm{c})$, see 42 U.S.C. $\$ 7412(d)(1)$, which requires the EPA to list categories of major sources of emitters of hazardous air pollutants. See 42 U.S.C. § 7412(c)(1). Source categories may relate to specific industries (e.g., petroleum refineries) or to stationary sources used in many industries (e.g., industrial heaters and boilers). See $i d$.

35. See 42 U.S.C. $\S 7412$.

36. See National Emission Standards for Hazardous Air Pollutants Streamlined Development: Announcement and Request for Comments, 60 Fed. Reg. 16,088, 16,089 (1995).

37. See id. at 16,090 . 
and state and local agencies would develop a draft presumptive MACT based on currently available information and technology. ${ }^{38}$ This meeting would be followed by a consultation step, in which industry and environmental groups would offer comments on the draft. ${ }^{39}$ Based on this imput, EPA, in conjunction with state and local agencies, would generate a final Presumptive MACT and choose a path for development of a formal standard. ${ }^{40}$ The public would be given opportunities to comment on this final step of phase one. ${ }^{41}$

API, along with others in the industry, had concerns about the Presumptive MACT process when EPA first instituted it. ${ }^{42}$ One niajor concern was that the regulated community would be excluded from the initial meetings among EPA and the state and local agencies, which could possibly lead to misunderstandings about the industry and about available control technologies at a very early stage in the regulatory process. API beheved these nisunderstandings inight lead to unnecessary delay and controversy. API also feared that a preliminary MACT determination, based on inconiplete data or analysis, and without technical input from or review by industry, might be adopted prematurely as a final state or local requirenient by a state or local agency, or even as a federal requirenient if EPA failed to issue a federal rule on schedule. ${ }^{43}$ A final concern was that, once a preliminary MACT was developed, it might be difficult for industry experts to persuade EPA that significant changes were needed before a reasonable and practical proposed rule could issue.

API has had experience with the Presumptive MACT process in connection with the development of a second rule restricting hazardous air pollutants from refinery processes, to be issued pursuant to section 112(d) of the Clean Air Act. This rule, referred to by the participants as "Refinery MACT II," is expected

38. See id.

39. See id.

40. See id.

41. See id.

42. See Letter from Paul Bailey, Director, Health and Environmental Affairs Department, API, to Albert H. Wehe, Environmental Engineer, Emission Standards Division, Office of Air and Radiation, EPA (May 15, 1995) (on file with author).

43. States must develop case-by-case MACT requirements if EPA fails to meet a promulgation deadline by eighteen months or more. See 42 U.S.C. $\S 7412(j)$ (1994). These requirements would be federal requirements. 
to be proposed im 1997 and promulgated in 1998. The Refinery MACT II rule will affect emissions of hazardous air pollutants from three refinery process vents not addressed in the first refinery MACT rule. ${ }^{44}$ A Presumptive MACT document was counpleted and made publicly available for informal comment in $1996,{ }^{45}$ and it has served as a useful basis for discussion. It summarized available data ${ }^{46}$ presented some tentative conclusions with respect to control options, ${ }^{47}$ and identified a number of issues needing additional data and further consideration. ${ }^{48}$

While API retains its general concerns with respect to the Presumptive MACT process described above, it has been satisfied with the process in comrection with the Refinery MACT II rule. EPA staff has been available to discuss relevant issues with API in meetings and conference calls, often with the participation of state representatives. The Presumptive MACT document does not appear to have formed the basis of any final requirement of which API is aware at this time.

As the experiences described above demonstrate, the evolving traditional rulemaking process can, given the right circumstances, confer many of the benefits of a reg neg without the disadvantages of a reg neg. API can discuss issues with EPA staff to develop sound, and even creative, regulatory approaches. EPA remains free to meet with other interested parties as well, and EPA can invite some or all interested parties to meet together if it decides such a meeting would be useful.

\section{B. Formal Stakeholder Processes}

The process described above is less useful if EPA is developing a rule that affects many different interests and parties. In such circumstances, EPA may decide that individual meetings would be too time-consuming but that a reg neg may not be the best format to air and resolve opposing views. EPA may therefore convene a wide group of interested persons pursuant to the Federal Advisory

44. See 40 C.F.R. $\S \S 63.640-.654$ (1996).

45. See EMISSION StandardS DIV., U.S. ENVTL. Protection AgenCY, PrelimiNARY PRESUMPTIVE MACT FOR PETROLEUM REFINERY PROCESS VENTS: FCC UNITS, REFORMERS, AND SULFUR PLANTS (1996).

46. See id. at app. B.

47. See id. at $25-29$.

48. See id. at 30. 
Committee Act, $^{49}$ in order to identify key issues and, if possible, to resolve thein.

These large group processes tend to share inany of the drawbacks of the reg neg process, such as significant expenditures of time and resources, often without providing the countervailing benefit of the resolution of difficult issues. For example, EPA held several years of meetings of a broad group of interested parties and of smaller work groups before issuing proposed amendinents to its Clean Air Act New Source Review and Prevention of Significant Deterioration (NSR) program, ${ }^{50}$ a complex preconstruction permitting process that EPA intended to simplify. The proposal subsequently has been attacked by inany commentators ${ }^{51}$ and appears likely to be litigated if the final rule bears a close resemblance to the proposal.

While the NSR stakeholder process identified areas of disagreement, the process did little to resolve the inajor issues. One reason for the relative lack of progress is that the parties were too far apart on a inajor portion of the eventual NSR proposal-revisions to requirements for protecting federal "Class I" areas (national parks and wilderness areas). While this portion of the rule was discussed, it did not appear to industry that there was inuch rooin for compromise. As one industry participant observed: "On these issues, the meetings were pointless. EPA had made its mind up that it would do what the federal land managers wanted." 52 It is not clear that the time and money consumed by the stakeholder process was well-spent.

Other reasons for the NSR stakeholder process's failure to achieve significant progress included: the absence of a deadline; the great number of participants with widely disparate views; and the coinplexity of many of the issues involved.

49. See 5 U.S.C. app. $2 \S 1$ 1-15 (1994).

50. See Prevention of Significant Deterioration (PSD) and Nonattainment New Source Review (NSR), 61 Fed. Reg. 38,250 (1996) (to be codified at 40 C.F.R. pts. 51-52) (proposed July 23,1996$)$.

51. See, e.g., Comments on EPA's New Source Review Proposal, 61 Fed. Reg. 38,250; Air Docket A-90-37 (submitted on behalf of the American Forest and Paper Association. the American Iron and Steel Institute, the American Petroleum Institute, the Association of International Automobile Manufacturers, and the National Mining Association on Jan. 21, 1997) (on file with author).

52. Interview with William Pedersen, Partner, Shaw, Pittman, Potts and Trowbridge, in Washington, D.C. (Mar. 28, 1997). Mr. Pedersen was a participant in the NSR stakeholder process. 
Another stakeholder process in which API has been involved over the past several years is one that EPA convened in connection with its "Common Sense Initiative" (CSI) program, which is part of the Clinton adininistration's federal governinent Reinvention Initiative. ${ }^{53}$ CSI groups were formed to address issues relating to a number of industries, including petroleum refining, ${ }^{54}$ in an effort to develop "cleaner," "cheaper," "smarter" ways to ensure environmental progress. ${ }^{55}$ The petroleum industry CSI group was composed of representatives of EPA, states, petroleum refiners, national environmental groups, environmental justice groups, and labor. ${ }^{56}$

The CSI group for the petroleum refining sector was formed in early $1995 .^{57}$ The petroleum industry, EPA, and others have devoted a considerable amount of time, effort, and expense to the CSI effort. The group has inade httle progress and, for a time, appeared likely to be disbanded. Activities have resumed, however.

Industry participants attribute the lack of progress in the petroleum refinery sector CSI project to several factors: 1) lack of a statutory deadline to drive the process forward; 2) lack of a specific agenda describing the issues the group would address; 3 ) too many participants; 4) procedural rules that had the effect of allowing one or two representatives to veto decisions to which the majority of the group would have agreed; 5) lack of strong leadership by EPA representatives; and 6) a noticeable feeling of distrust among some of the participants. ${ }^{58}$

53. See President Bill Clinton \& Vice President Al Gore, Reinventing ENVIRONMENTAL REGULATION 15, 50 (1995).

54. See Common Sense Initiative Council Federal Advisory Committee, 59 Fed. Reg. 55,117, 55,117 (1994) (establishment) [hereinafter CSI Council Establishment].

55. Addition of Reporting Elenents; Toxic Chemical Release Reporting; Community Right-to-Know, 61 Fed. Reg. 51,322, 51,326 (1996) (advanced notice of proposed rulemaking).

56. See CSI Council Establishment, supra note 54, at 55,117.

57. See Common Sense Initiative Oil Refining Sector, Meeting Notice, 60 Fed. Reg. 4619,4619 (1995) (giving notice of the initial meeting to be held Feb. 9-10, 1995).

58. The observations here are those of API participants in the CSI project, as expressed in personal and telephone interviews. Interview with Walter McLeod, API Staff Member, in Washington, D.C. (Mar. 21, 1997); Teleplione Interview with John Medley, Coordinator, Environmental, Health and Safety Issues, Mobil Corporation (Mar. 26, 1997); Telephone Interview with Arthur Lee, Senior Environmental Engineer, Texaco Corporation (Mar. 27, 1997). 
The NSR and CSI stakeholder processes illustrate that there are several disadvantages to these other multistakeholder processes as compared to reg negs: participants do not come to the table with the same commitment to resolve issues as they would in a reg neg; the processes are not well-focused; and too many participants are often mvolved. As mechanisms to air and identify issues, stakeholder processes can be effective, but they are not well suited to issue resolution.

\section{CONCLUSIONS}

EPA now uses a variety of rulemaking processes. There is no single best approach. Reg negs can be effective tools for crafting creative solutions and providing certainty. These benefits are not always achieved, however, and reg negs place considerable time and resource demands on participants. A reg neg is most likely to be successful if issues and participants are carefully selected. For example, issues that are highly political are not good reg neg candidates. Outside factors can also affect the success or failure of a reg neg. Statutory or consent decree deadlines will nake it more likely that a reg neg will succeed. Trade associations like API are likely to approach reg negs with skepticisin and are most likely to agree to participate in a reg neg if other options are foreclosed and EPA exerts pressure for thein to participate.

The traditional, notice-and-comment rulemaking process, as it is evolving at EPA, can offer many of the advantages of a reg neg and is preferable if EPA staff are agreeable to meeting with different interests individually. Industry can benefit if it generates information that EPA finds useful and responsive to agency concerns. The apparent certainty of a reg neg is lacking, however, and the process is entirely under the control of EPA staff.

Overall, however, broad stakeholder processes are difficult to manage successfully and often have all the drawbacks of a reg neg with few of the advantages. They are most useful in airing issues rather than resolving them. 
. 